\title{
Redescription of Conniella apterygia Allen and its reassignment in the genus Cirrhilabrus Temminck and Schlegel (Teleostei: Labridae), with comments on cirrhilabrin pelvic morphology
}

\author{
YI-KAI TEA ${ }^{1,2}{ }^{*}$, GERALD R. ALLEN ${ }^{3}$, CHRISTOPHER H. R. GOATLEY ${ }^{2,4,5}$, \\ ANTHONY C. GILL ${ }^{1,2,6}$ \& BENJAMIN W. FRABLE ${ }^{7}$ \\ ${ }^{I}$ School of Life and Environmental Sciences, University of Sydney, New South Wales 2006, Australia. \\ ${ }^{2}$ Ichthyology, Australian Museum Research Institute, 1 William Street, Sydney, New South Wales 2010, Australia. \\ ${ }^{3}$ Department of Aquatic Zoology, Western Australian Museum, Locked Bag 49, Welshpool DC, Perth, Western Australia 6986, Austra- \\ lia. $\equiv$ Gerry.tropicalreef@gmail.com \\ ${ }^{4}$ Function, Evolution and Anatomy Research (FEAR) Lab, School of Environmental and Rural Science, University of New England, \\ Armidale, NSW, 2351, Australia. "Christopher.goatley@une.edu.au; 으ttps://orcid.org/0000-0002-2930-5591 \\ ${ }^{5}$ School of Aquatic and Fisheries Sciences and the Burke Museum of Natural History and Culture, University of Washington, 1122 NE \\ Boat Street, Seattle, WA 98105, USA \\ ${ }^{6}$ Macleay Collections, Chau Chak Wing Museum, University of Sydney, New South Wales 2006, Australia. I”"Anthony.c.gill@sydney. \\ edu.au; ㄴ) https://orcid.org/0000-0002-8990-3657 \\ ${ }^{7}$ Marine Vertebrate Collection, Scripps Institution of Oceanography, University of California San Diego, 9500 Gilman Drive, La Jolla,

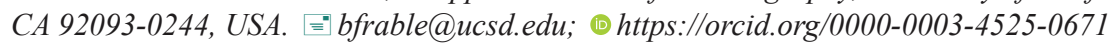 \\ "Corresponding author: !"yi-kai.tea@sydney.edu.au; @ i https://orcid.org/0000-0002-2146-2592
}

\begin{abstract}
Conniella apterygia is redescribed from re-examination of the holotype, two paratypes, and six additional specimens. The genus is closely allied to Cirrhilabrus, sharing similarities in general morphological and meristic details, but is separated from Cirrhilabrus and most other labrid fishes in lacking pelvic fins and a pelvic girdle. Recent molecular phylogenetic studies have provided strong evidence for the deep nesting of Conniella within Cirrhilabrus, contradicting its generic validity and suggesting that the loss of pelvic elements is autapomorphic. Consequently, the species is redescribed and assigned to the genus Cirrhilabrus, as Cirrhilabrus apterygia new combination. The pelvic morphologies of related cirrhilabrin labrids are discussed, and a new synapomorphy is identified for Paracheilinus.
\end{abstract}

Key words: coral-reef fishes; taxonomy; ichthyology; apomorphy; fairy wrasse; morphology

\section{Introduction}

Allen (1983) described Conniella apterygia from three specimens collected at Clerke Reef, Bedwell Island, Rowley Shoals, Western Australia. The species is unusual among labrid fishes in lacking pelvic fins and a pelvic girdle, a peculiarity that provided sole justification for the erection of a new genus and its accompanying species. Conniella has been regarded as closely allied to Cirrhilabrus Temminck \& Schlegel, 1845 (Allen 1983; Randall 1999), and although the absence of pelvic elements serves to distinguish the two genera, both are united by the following character combination that distinguishes them from related genera: dorsal-fin rays XI,9; dorsal-fin spines tipped with fibrous cirri; lateral line interrupted; upper jaw with three pairs of enlarged canines; and preopercle margin serrated.

Further justification for the recognition of Conniella as a distinct genus from Cirrhilabrus has been scant. Similarly, there has been a lack of systematic studies of related "pseudocheilines" sensu Westneat (1993), originally proposed as an informal group within the Labridae comprising the following genera: Cirrhilabrus; Paracheilinus Fourmanoir, 1955 [in Roux-Estève \& Fourmanoir 1955]; Pseudocheilinus Bleeker, 1862; Pseudocheilinops Schultz, 1960 [in Schultz et al. 1960]; and Pteragogus Peters, 1855. Further, there has been no consistent use of terminology for the genera above, and few studies have included adequate representation of all component genera. 
Westneat (1993) united the five genera based on the following four synapomorphies: third premaxillary canine elongate and recurved; anterior portion of ceratohyal bearing a ventral hook; nasal with posterior flange; and scleral cornea bisected into two foci. Conniella was not included in the study, but the genus was later briefly considered by Randall (1999) as a member of the Cirrhilabrini in his revision of the genus Pseudocheilinus. Besides the use of "pseudocheilines," other collective group names for these fishes have been proposed, such as the cirrhilabroid fishes (Springer \& Randall 1974), the Cirrhilabrini (Randall, 1999), and the Pseudocheilini (Cowman et al. 2009; Bannikov \& Carnevale 2010; Almeida et al. 2017). The lattermost appears to be a noun formed either from the stem genus-group name Pseudocheilinus or from the collective "pseudocheilines," used as a scientific name for a suprageneric taxon, and ending in a family-group name suffix, but without a diagnosis. Of the names used, only Cirrhilabrini meets the requirements for a validly proposed family-group name (International Commission on Zoological Nomenclature 1999: Arts. 11.7, 13, 29). However, it was overlooked by Van der Laan et al. in both their original (2014) and updated (2021) list of family-group names. Because the other names do not meet those requirements (i.e., the name is used only as a collective adjective), and as we are unaware of any other family-group names based on any of the included genera or their synonyms, we recognise Cirrhilabrini Randall, 1999 as a valid tribe for the group.

In addition to morphological similarities between Conniella and Cirrhilabrus, recent phylogenomic studies on cirrhilabrin relationships reveals that Conniella is deeply nested within Cirrhilabrus (Tea et al.2021b). Because the generic recognition of Conniella would result in a non-monophyletic Cirrhilabrus, we propose subsuming it within the synonymy of Cirrhilabrus. Cirrhilabrus apterygia new combination is redescribed based on the holotype, two paratypes, and six additional specimens. The pelvic morphology of the cirrhilabrins is briefly discussed, and a new synapomorphy is proposed for Paracheilinus.

\section{Materials and methods}

Methods for counting and measuring follow Randall \& Masuda (1991), except gill rakers are presented as upper (epibranchial) + lower (ceratobranchial); the angle raker is included in the second count. Counts of lateral-line scales are given in two parts, the dorsoanterior series and the midlateral peduncular series. The latter series includes the larger pored scale overlapping the caudal-fin base, which we incorporate in the count. In the following description, data are presented first for the holotype, followed by the minimum-maximum values from paratypes and additional specimens in parentheses where different. Where counts were recorded bilaterally, both counts are given and separated by a slash; the first count presented is from the left side. Morphometric values are expressed as percentages of standard length (Table 1).

Osteological details were taken from micro-computed tomographic $(\mu \mathrm{CT})$ data and examination of cleared and stained specimens. To maximise scan resolution around the pelvic girdle, scans of the anterior half of Conniella apterygia (NMV A 29675-010) and Cirrhilabrus solorensis (AMS I.46121-036) were made on a GE Phoenix V|tome|x $\mathrm{S}$ industrial $\mu \mathrm{CT}$ scanner at the University of New England, Armidale. A scan of the anterior half of Paracheilinus octotaenia (uf:fish:186029) was downloaded from Morphosource.org (ark:/87602/m4/M168033) and used for comparison. Segmentation and visualisation of all scans were performed using 3D Slicer 4.11 (Fedorov et al. 2012; Slicer.org 2021), following methods described in Buser et al. (2020). All new scan data were archived on Morphosource.org (ark:/876002/m4/392169 and ark:/87602/m4/392175).

Methods of dissection follow Weitzman (1974). Terminology for the pelvic girdle follows Stiassny \& Moore (1992). Institutional codes follow Sabaj (2020). We follow Randall (1999) in recognising Cirrhilabrini as a valid tribe that includes Cirrhilabrus, Paracheilinus, Pseudocheilinus, Pseudocheilinops, and Pteragogus (see justification in Introduction).

\section{Identity of Conniella apterygia}

The general morphology, meristic values, dentition, serrations on the preopercle, and fin shape of Conniella apterygia are in general agreement with the genus Cirrhilabrus. In particular, the lanceolate caudal fin is unusual among cirrhilabrin genera, but typical for several species of Cirrhilabrus. Elongation of the central principal caudal-fin rays also occurs for one species of Paracheilinus (P. attenuatus Randall, 1999). However, Conniella apterygia differs 
from P. attenuatus and all other species of Paracheilinus in having XI,9 dorsal rays (versus IX,11), serrations on the preopercle, and in lacking filamentous segmented dorsal-fin rays.

The absence of pelvic fins and the pelvic girdle has been the sole justification separating Conniella from Cirrhilabrus. Owing to the rarity of Conniella, complete representation of the cirrhilabrins has been lacking in both morphological and molecular studies. These relationships have recently been investigated for the first time using a large phylogenomic dataset, revealing Conniella to be deeply nested within Cirrhilabrus (Tea et al. 2021b). Due to the current lack of a morphological diagnosis supporting Conniella, and its nested position within Cirrhilabrus in the molecular phylogeny of Tea et al. (2021b), we recommend placement of Conniella within the synonymy of Cirrhilabrus.

\section{Cirrhilabrus apterygia (Allen, 1983), new combination}

Connie's Wrasse

Other names: Mutant Wrasse; Rowley Shoals Wrasse

Figures 1, 2A-B, 2E-F, 3A, 4B; Table 1.

Conniella apterygia Allen 1983 (Holotype WAM P.27659-006; type locality Bedwell Island, Clerke Reef, Rowley Shoals, Western Australia): Allen \& Russell 1986 (checklist; Rowley Shoals, Scott Reef, and Seringapatam Reef).-Allen \& Steene 1987: 151, pl 87-1 (colour photograph).-Parenti \& Randall 2000 (annotated checklist of labroid fishes). - Hoese et al. 2006 (checklist; Zoological Catalogue of Australia).-Kuiter 2010: 154 (colour photographs A-F; specimens photographed from Rowley Shoals).- Allen 2018: 211, pl 74-14 (illustration).-Parenti \& Randall 2018 (annotated checklist of labroid fishes).- Swainston 2020: 630 (checklist of Australian labrid species). - Tea et al. 2021b (included as part of a phylogenomic study of Cirrhilabrus).

Diagnosis. A species of Cirrhilabrus distinguished from all other congeners based on the following combination of colouration and morphological characters: absence of pelvic fins and pelvic girdle; lateral line with 21-26 pored scales (16-17 in the dorsoanterior series, 5-9 in the posterior peduncular series); caudal fin rhomboidal to lanceolate in males; both sexes with eight to ten stripes, purple in life and in preservation; preopercle purple in preservation.

Description. Dorsal-fin rays XI,9 (one specimen with X,9); all soft rays branched except first ray unbranched (one specimen with first ray branched); anal-fin rays III,9; all soft rays branched except first ray unbranched; last dorsal and anal-fin ray branched to base; pectoral-fin rays 15 (one specimen with 15/13), upper two unbranched; principal caudal-fin rays $7+6$, uppermost and lowermost unbranched; upper procurrent caudal-fin rays 6 , lower procurrent caudal-fin rays 6; lateral line interrupted, with dorsoanterior series of pored scales 17 (16-17) and midlateral posterior peduncular series 9 (5-9); first pored scale on posterior peduncular series often pitted; last pored scale on posterior peduncular series enlarged and overlapping hypural crease; scales above lateral line to origin of dorsal fin 2; scales below lateral line to origin of anal fin 6; median predorsal scales 5; rows of scales on cheek 2; circumpeduncular scales 16; gill rakers $7(6-7)+9(9-11)=16(15-18)$; pseudobranchial filaments 12 (10-12); vertebrae 9+16; epineurals 12 (Fig. 4B).

Body moderately elongate and compressed, depth $3.6(3.2-3.8)$ in SL, width 2.2 (2.0-2.5) in depth; head length (HL) 3.1 (3.0-3.5) in SL; snout pointed, its length 4.3 (3.2-3.9) in HL; orbit diameter 3.8 (3.0-3.6) in HL; depth of caudal peduncle $2.1(2.0-2.4)$ in HL. Mouth small, terminal, and oblique, with maxilla almost reaching vertical at front edge of orbit; dentition typical of the genus with three pairs of canine teeth present anteriorly at side of upper jaw, first forward-projecting, next two strongly recurved and outcurved, third longest; an irregular row of very small conical teeth medial to upper canines; lower jaw with a single stout pair of canines anteriorly which protrude obliquely outward and are slightly lateral to medial pair of upper jaw; no teeth on roof of mouth.

Posterior margin of preoperculum with 44/45 (32-45) very fine serrations; margins of posterior and ventral edges of preoperculum free to about level of middle pupil. Anterior nostril in short membranous tube, located nearer to orbit than snout tip; posterior nostril larger, roughly ovoid to rectangular, located just medial and anterior to upper edge of eye. Scales cycloid; head scaled except snout and interorbital space; 6 (6-7) large scales on opercle; a broad naked zone on membranous edge of preopercle; a row of large, elongate, pointed scales along base of dorsal fin, one per element, scales progressively shorter posteriorly on soft portion of fin; anal fin with a similar basal row of scales; last pored scale of lateral line (posterior to hypural plate) enlarged and pointed; one scale above and below last pored scale also enlarged; pectoral fins naked except for a few small scales at fleshy base. 


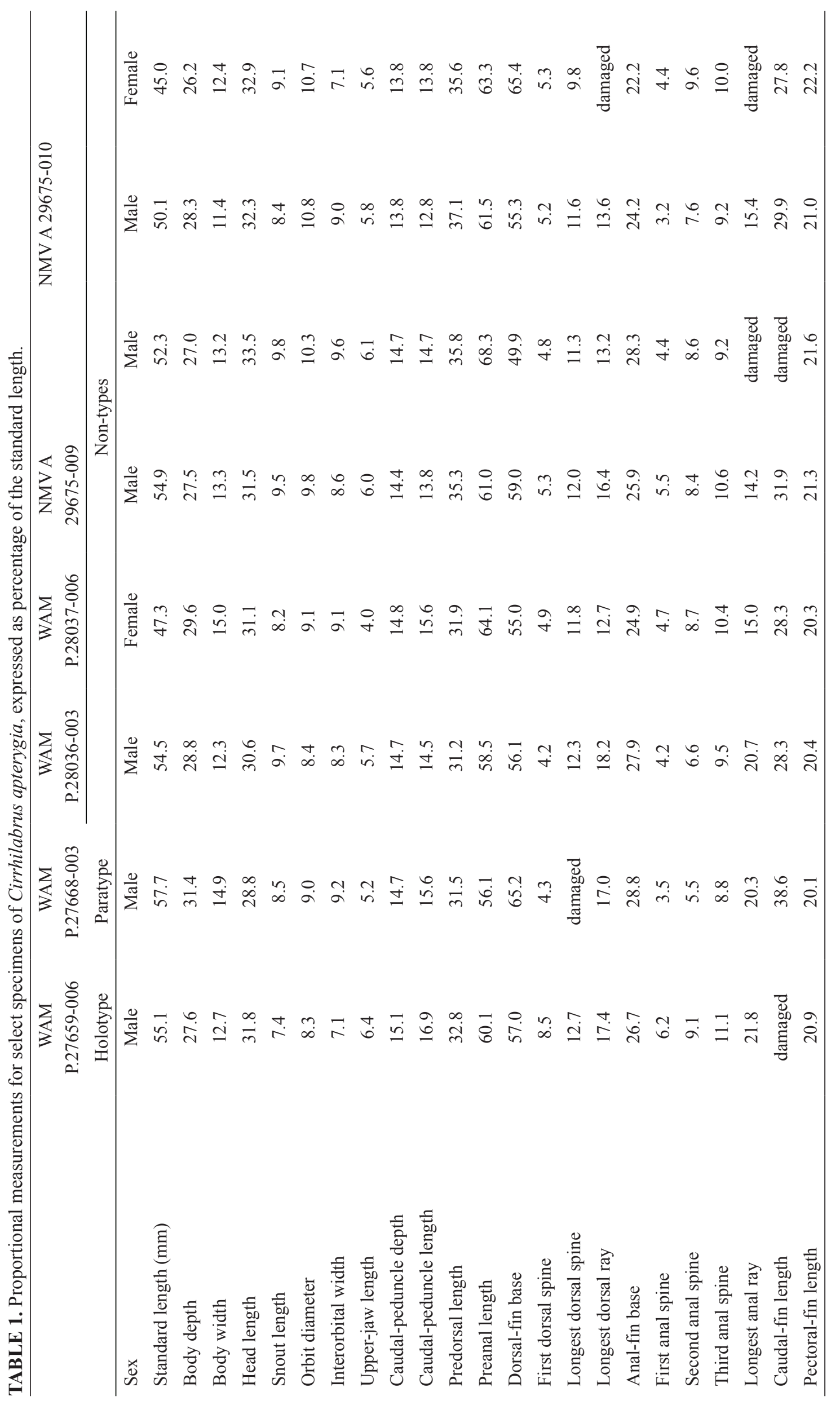



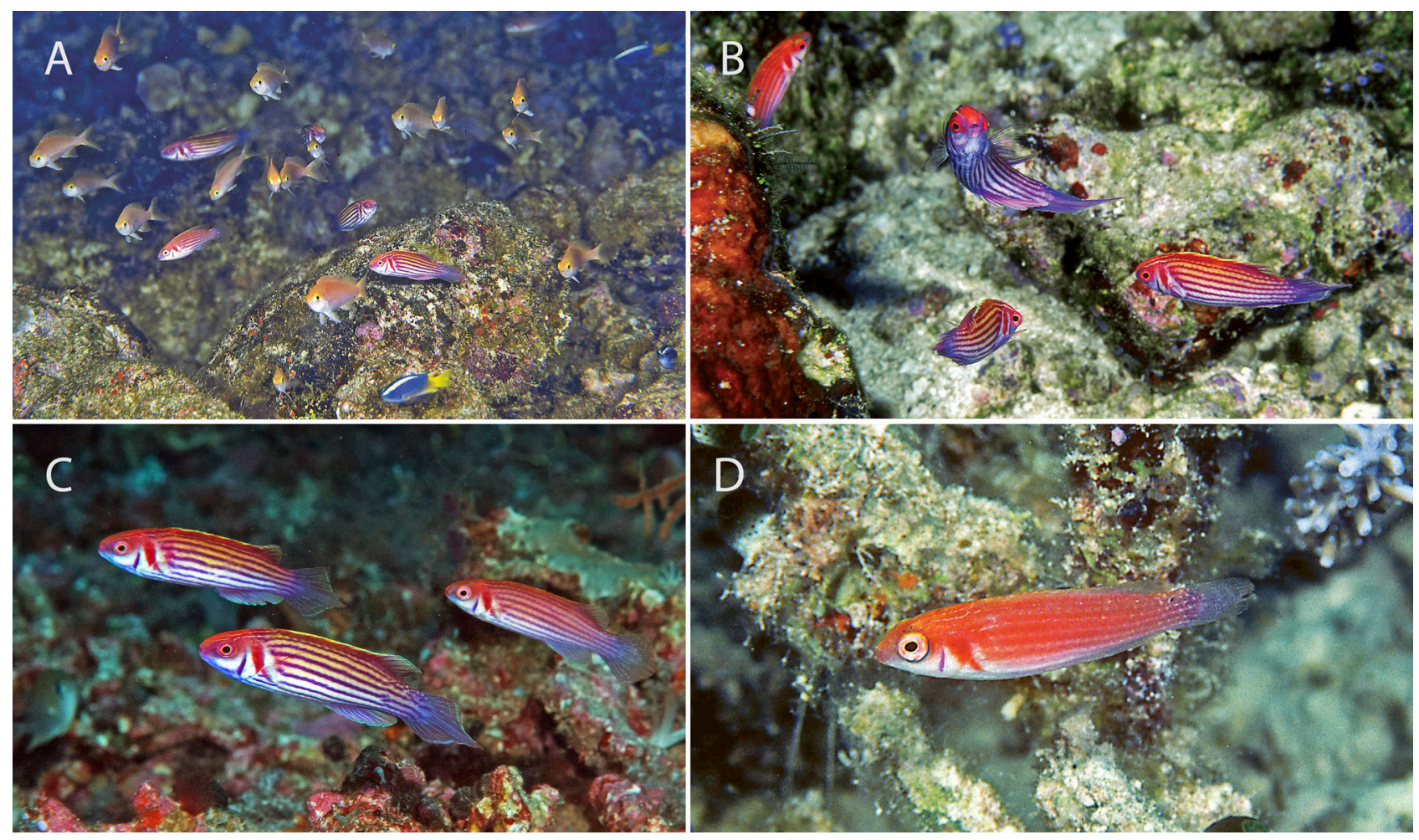

FIGURE 1. Cirrhilabrus apterygia, underwater photograph from Rowley Shoals, Western Australia. (A-C) Males and females in loose groups; (D) juvenile, approximately $35 \mathrm{~mm}$ total length. Note mixed aggregations of Pseudanthias engelhardi and Chrysiptera caeruleolineata in (A). Note individual showing ventral stripes from isthmus to anal-fin origin in (B). Photographs by R.H. Kuiter (A, B, D) and G.R. Allen (C).

Origin of dorsal fin above second or third lateral-line scale, predorsal length 3.0 (2.7-3.2) in SL; first 1-5 dorsal-fin spines progressively longer, sixth to ninth subequal, 10th to 11th longest, 2.5 (2.5-3.4) in HL; interspinous membranes of dorsal fin in males extend beyond dorsal-fin spines, with each membrane extending in a pointed cirrus beyond spine; 8th to 9th dorsal-fin soft ray longest, 1.8 (1.7-2.5) in HL, remaining rays progressively shorter; origin of anal fin below base of 9th dorsal-fin spine; third anal-fin spine longest, 2.9 (1.7-2.5) in HL; interspinous membranes of anal fin extended as on dorsal fin; anal-fin soft rays relatively uniform in length, 7th to 9th longest, 1.5 (1.4-2.2) in HL; dorsal- and anal-fin rays just reaching past caudal-fin base; caudal fin of males rhomboidal to lanceolate; pectoral fins short, reaching vertical between bases of 6th or 7th dorsal-fin spines, longest ray 1.5 (1.4-1.5) in HL; pelvic fins and pelvic girdle.

Colouration of males in life. Based on colour photographs of specimens when freshly dead, and photos of live individuals taken in the field (Figs. 1A-C, 2A-B, \& 3A): head orange-purple above, often magenta washed, abruptly white to cream below lower limit of orbit; interorbital region and nape orange-red, with four to five thin white lines from just above nostrils to dorsal-fin origin; lavender stripe present from lower edge of maxilla to anterior orbit; iris lavender, with orange ring around pupil; distal edge of orbit yellow; lower margin of cheek to outer margin of preopercle bright purple; interopercle purple; operculum white, broadly edged posteriorly with a reddish purple bar, connecting ventrally with oblique reddish purple wedge over pectoral-fin base; body cream to pale yellow above, gradually lightening to white ventrally; body with eight to ten bright purple stripes, first six starting a short distance behind reddish purple opercular and pectoral-fin markings, so as to form an intervening white wedge of similar width; remaining stripes originating from lower edge of opercle and isthmus; all stripes terminate at base of caudal fin, except ventralmost two to three stripes terminating at anal-fin origin; dorsal fin translucent yellow; anterior spinous dorsal fin with two submarginal, parallel yellow stripes breaking into indistinct spots and short stripes toward soft dorsal fin; outermost margin of dorsal fin narrowly bright blue; scales at base of dorsal fin magenta to fuchsia; caudal fin translucent pink to yellow with a pair of prominent blue chevrons converging at caudal-fin terminus, central region often with yellow and blue spots and short stripes; anal fin similar to dorsal fin; pectoral fins translucent pink, distal edge more strongly coloured. 


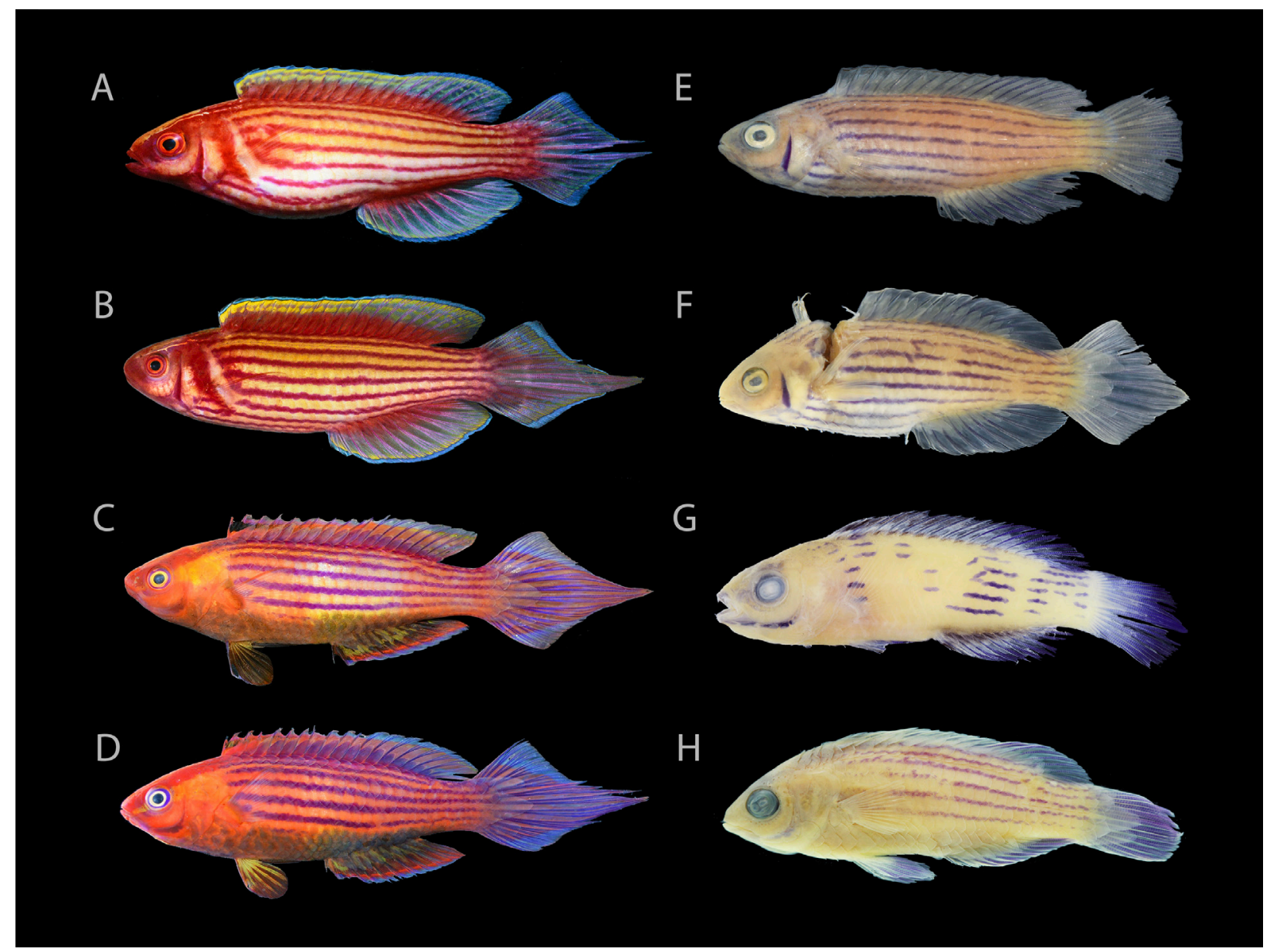

FIGURE 2. A selection of freshly euthanised (A-D) and preserved Cirrhilabrus species (E-H). (A) Cirrhilabrus apterygia, WAM P.28037-006, 67 mm SL, male, Clerke Reef, Rowley Shoals, Western Australia; (B) Cirrhilabrus apterygia, USNM FIN 29616, 75.0 mm SL, male, Mermaid Reef, Rowley Shoals, Western Australia; (C) Cirrhilabrus earlei, BPBM 41386, approximately $100 \mathrm{~mm}$ SL, male, Pohnpei, Micronesia; (D) Cirrhilabrus earlei, BPBM 41387, approximately $100 \mathrm{~mm}$ SL, male, Pohnpei, Micronesia; (E) Cirrhilabrus apterygia, WAM P.27659-006. 55.1 mm SL, male holotype, Clerke Reef, Rowley Shoals, Western Australia; (F) Cirrhilabrus apterygia, WAM P.27668-003, 57.7 mm SL, male paratype, same data as holotype; (G) Cirrhilabrus earlei, ZRC 60866, 69.4 mm SL, male, Marshall Islands, Micronesia (image right side reversed); (H) Cirrhilabrus earlei, CAS 213114, $56.5 \mathrm{~mm}$ SL, male paratype, Augulpelu Reef, Palau. Note damage from spear in (F), and missing scales in (G). Photographs by G.R. Allen (A); J.E. Randall (B); B. D. Greene (C-D); Y.K. Tea (E-F); H.H. Tan (G); and B.W. Frable (H).

Colouration of females and juveniles in life. Based on colour photographs of specimens when freshly dead, and photos of live individuals taken in the field (Fig. 1B-D): similar to males, except bars and stripes on body less pronounced, and body colouration pinkish; caudal fins of females rounded or weakly rhomboidal and without blue chevron markings; distal edge of caudal peduncle with a very small black spot.

Colouration in alcohol. Based on colour photographs of preserved specimens (Fig. 2E-F): similar to life, except body uniformly tan; several osseous elements remain purple, including purple scale markings on body, median-fin spines and rays, infraorbitals, maxilla, premaxilla, dentary, anguloarticular, and preopercle; black spot on distal edge of caudal peduncle in females and juveniles remains.

Habitat and distribution. Cirrhilabrus apterygia occurs on offshore reefs off northwestern Western Australia, including Rowley Shoals, Scott, and Seringapatam Reefs. ROV dive footage from the RV Falkor's Australian Mesophotic Coral Exploration cruise indicates that the species also occurs on Ashmore Reef, $840 \mathrm{~km}$ west of Darwin, Northern Territory. It frequents rubble bottoms covered with macroalgae cover at depths between 20-60m, but also occurs in mesophotic coral ecosystems as deep as $140 \mathrm{~m}$.

Etymology. Allen (1983) named the species apterygia, meaning "without fins," in reference to the distinctive 
lack of pelvic fins and associated elements. To be treated as a noun in apposition. We retain the use of Connie's Wrasse as the preferred common name, after Connie Lagos Allen, wife of the second author, for whom the junior synonym Conniella was named. The species is also commonly referred to as the mutant wrasse, alluding to its atypical pelvic morphology, as well as the eponymous Rowley Shoals Wrasse, after its type locality.
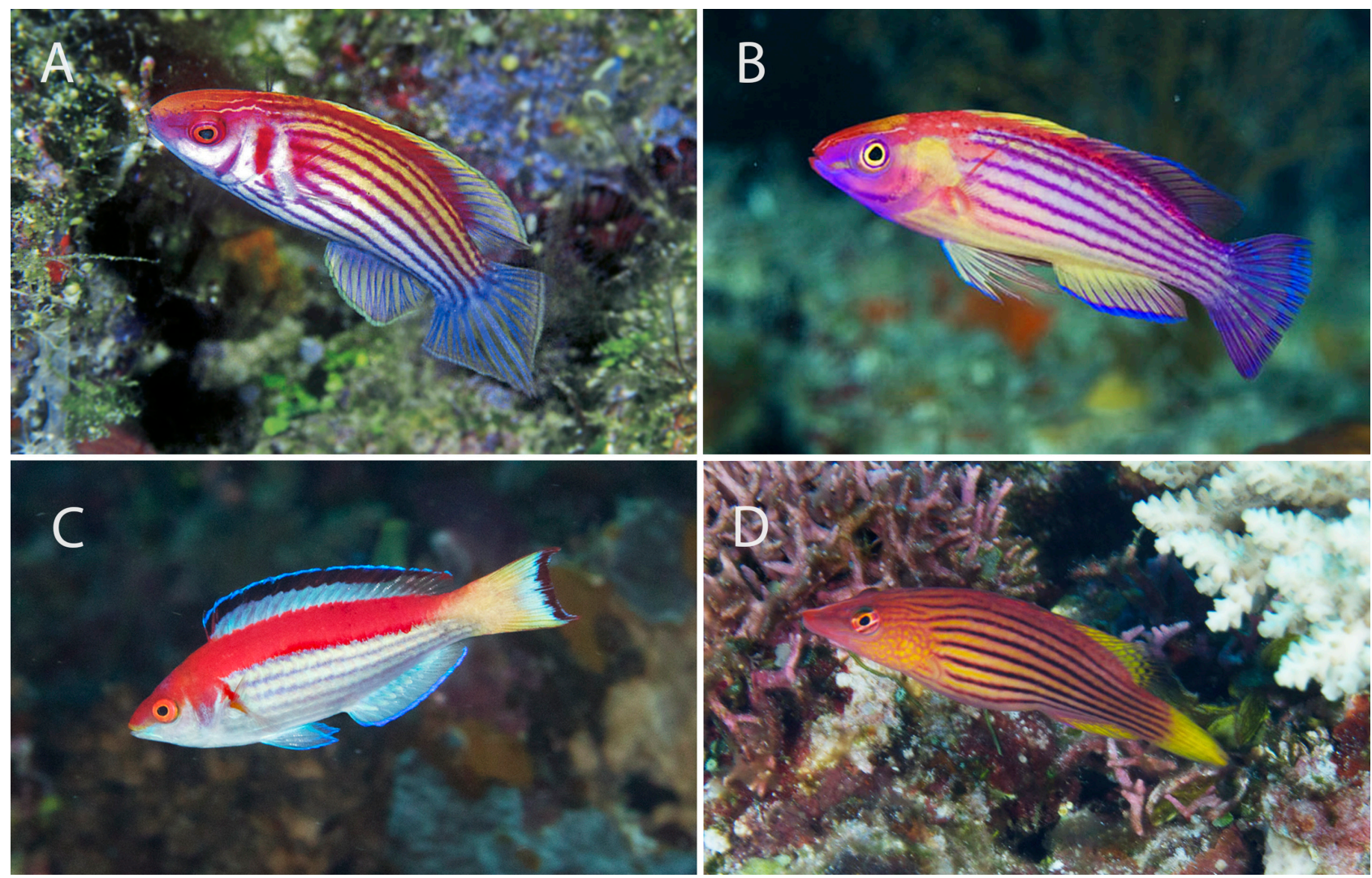

FIGURE 3. A selection of cirrhilabrin labrids with horizontal striped patterns. (A) Cirrhilabrus apterygia, underwater photograph from Rowley Shoals; (B) Cirrhilabrus earlei, underwater photograph from Koror, Palau; (C) Cirrhilabrus marjorie, underwater photograph from Vanua Levu, Fiji; (D) Pseudocheilinus octotaenia, underwater photograph from Levuka, Fiji. Photographs by R.H. Kuiter (A); K. Nishiyama (B); and M. Rosenstein (C-D).

Material examined. Cirrhilabrus apterygia: WAM P.27659-006 (holotype), $55.1 \mathrm{~mm} \mathrm{SL}$, male, outer reef slope east of Bedwell Island, Clerke Reef, Rowley Shoals, Western Australia, 32 m, 22 July 1982 (Fig. 2E); WAM P.27668-003 (paratype), $57.7 \mathrm{~mm} \mathrm{SL}$, male, same data as holotype except collected at $35 \mathrm{~m}, 27$ July 1982 (Fig. 2F); WAM P.27668-015 (paratype), $31.2 \mathrm{~mm} \mathrm{SL}$, female, same data as male paratype (specimen cleared and stained; Fig. 4B); WAM P.28036-003, $54.5 \mathrm{~mm}$ SL, male, Clerke Reef, outer reef $1 \mathrm{~km}$ off southern tip of Bedwell Island, Rowley Shoals, Western Australia, 20-35 m, 13 August 1983; WAM P.28037-006, 47.3 mm SL, male, same data as WAM P.28036-003 except collected at 45-50 m, 14 August 1983; NMV A 29675-009, 54.9 mm SL, male, Cunningham Island, Imperieuse Reef, Rowley Shoals, Western Australia, 108-140 m, 16 June 2007; NVM A 29675010, 3 specimens, 45.0-52.3 mm SL, two males and one female, same data as NVM A 29675-009. Cirrhilabrus earlei: ZRC 60866, 69.4 mm SL, male, Marshall Islands, Micronesia (Fig. 2G); CAS 213114 (paratype), 56.5 mm SL, male, Augulpelu Reef, Palau (Fig. 2H). Cirrhilabrus rubrimarginatus: AMS I.45300.288, 43.8 mm SL, (specimen cleared and stained; Fig. 4A). Cirrhilabrus naokoae: AMS I.45300.513, $49.1 \mathrm{~mm}$ SL, (specimen cleared and stained). Paracheilinus lineopunctatus: AMS I.45300.194, $51.0 \mathrm{~mm} \mathrm{SL}$, (specimen cleared and stained; Fig. 4C). Paracheilinus mccoskeri: AMS I.45300.185, 5 specimens, 31.0-54.5 mm SL, (specimens cleared and stained). Pseudocheilinus ocellatus: AMS I.45300.485, $48.8 \mathrm{~mm} \mathrm{SL}$, (specimen cleared and stained). Pseudocheilinops ataenia: AMS I.45300.056, 2 specimens, 24.1-34.7 mm SL (specimen cleared and stained). Pteragogus flagellifera: AMS I.187755-034, $52.0 \mathrm{~mm} \mathrm{SL}$, (specimen cleared and stained). 

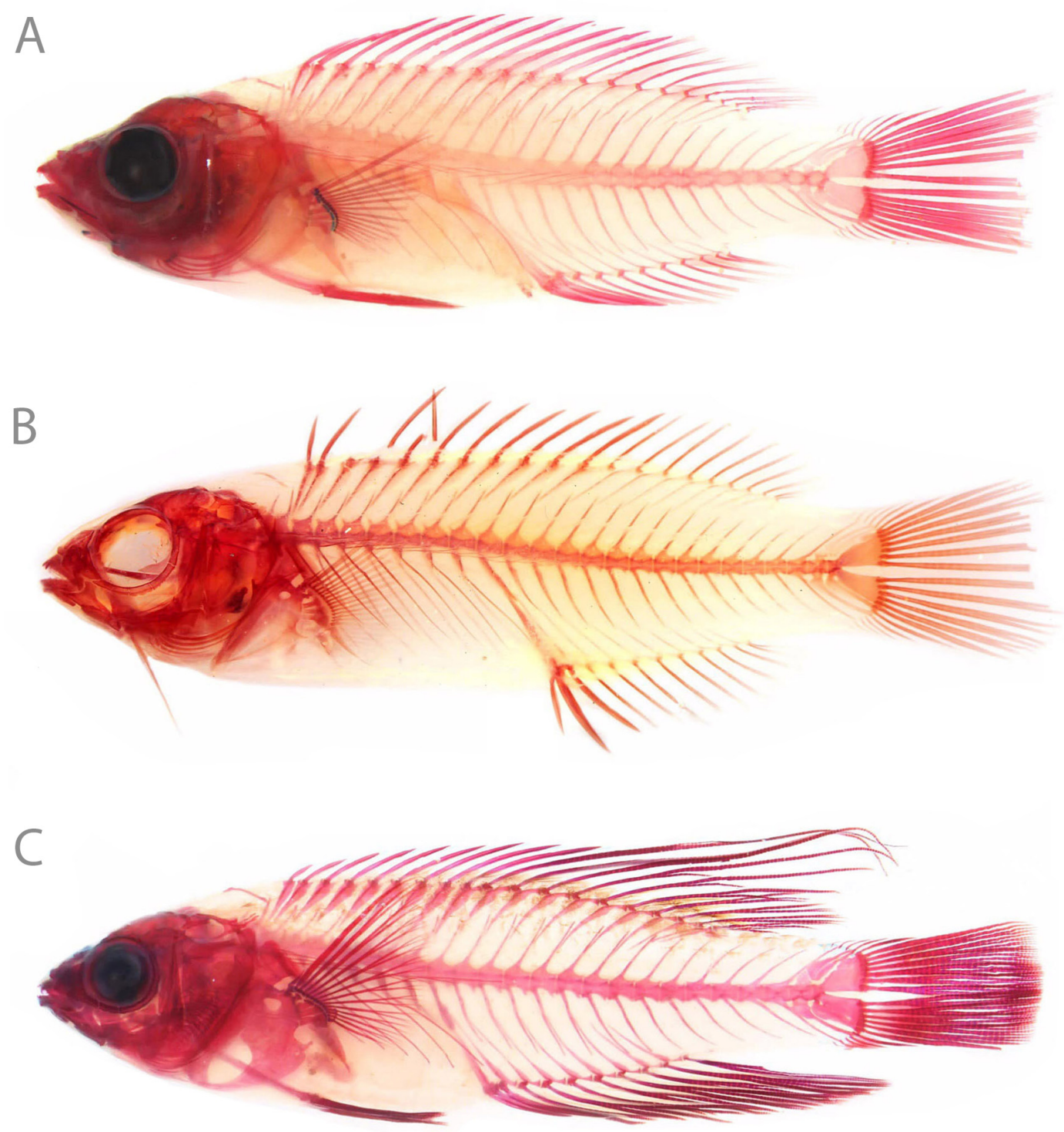

FIGURE 4. Cleared and stained pseudocheiline labrids. (A) Cirrhilabrus rubrimarginatus, AMS I.45300.288, 43.8 mm SL; (B) Cirrhilabrus apteyrgia, WAM P.27668-015, 31.2 mm SL, female paratype, Clerke Reef, Rowley Shoals, Western Australia; (C) Paracheilinus lineopunctatus, AMS I.45300.194, $51.0 \mathrm{~mm}$ SL. Note displaced urohyal in (B).

\section{Comparison with other Cirrhilabrus species}

Cirrhilabrus apterygia belongs to the Cirrhilabrus jordani complex of fairy wrasses (Tea et al. 2021b), a lineage whose species are diagnosed based on the following combination of characters: pelvic fins relatively short (not or barely reaching anal-fin origin; absent in C. apterygia); a pair of stripes on head (in both sexes; strongly evident during male nuptial display); and dorsal and anal fins without obvious stripes or spots. Tea and Gill (2017) previously included $C$. claire Randall \& Pyle, 2001 as a member of the $C$. jordani complex, though its phylogenetic position remained unclear and was only recently resolved based on a large molecular dataset (as a member of the $C$. lineatus complex; Tea et al. 2021b). The taxonomy of the related C. rubrisquamis Randall \& Emery, 1983 from the western Indian Ocean is muddled, and the name is currently applied to several fishes with notable differences in colour pattern and morphology (in prep. by the first author). Until this situation is resolved, we use C. rubrisquamis sensu lato to refer to the nominal taxon, as well as any others presently lumped under this name. The $C$. jordani complex is tentatively redefined to include the following species: Cirrhilabrus apterygia, C. blatteus Springer \& Randall, 1974 , C. earlei Randall \& Pyle, 2001, C. jordani Snyder, 1904, C. lanceolatus Randall \& Masuda, 1991, C. roseafascia Randall \& Lubbock, 1982, C. rubrisquamis sensu lato, C. sanguineus Cornic, 1987, C. shutmani Tea \& Gill, 2017, and C. wakanda Tea, Pinheiro, Shepherd \& Rocha, 2019. 

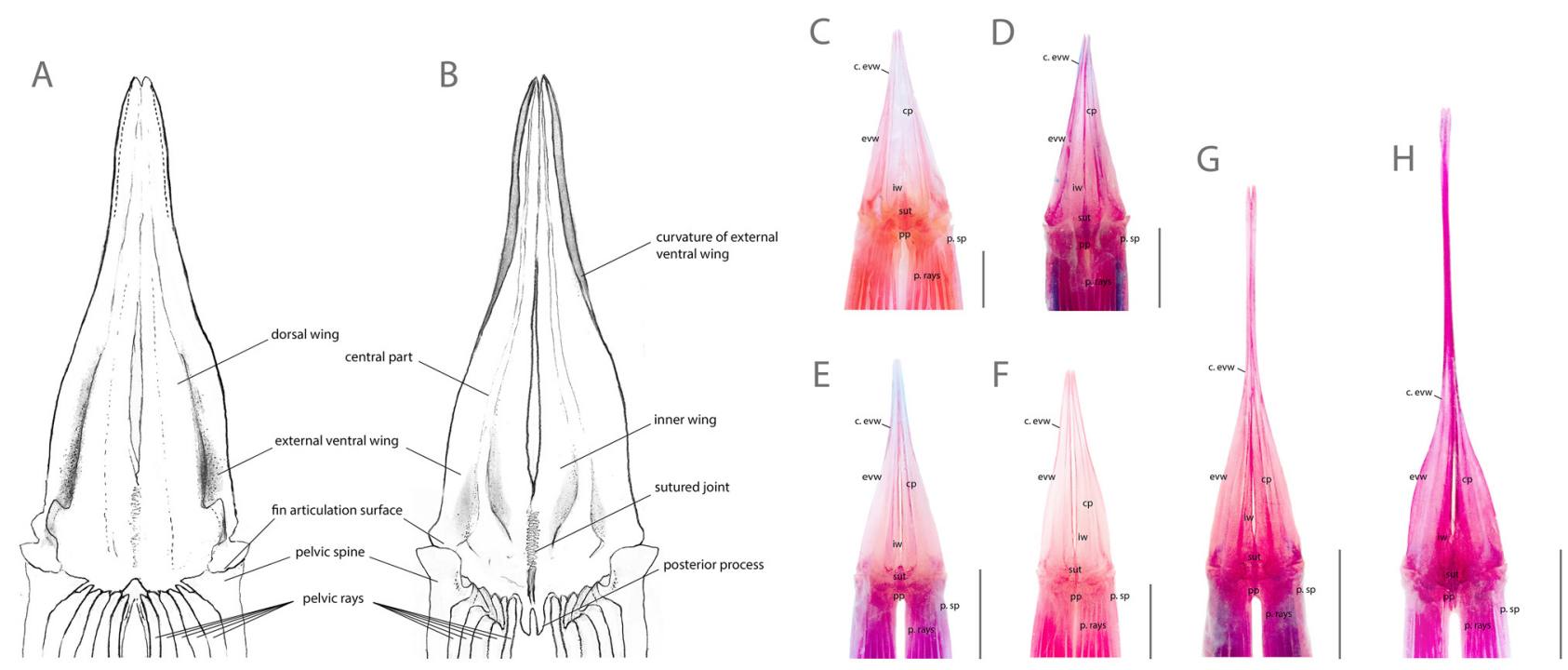

FIGURE 5. Schematic diagram of Cirrhilabrus pelvic girdle anatomy in (A) dorsal view and (B) ventral view. Cleared and stained pelvic girdles of: (C) Pteragogus flagellifera, AMS I.187755-034; (D) Pseudocheilinops ataenia, AMS I.45300.056; (E) Pseudocheilinus ocellatus, AMS I.45300.485; (F) Cirrhilabrus rubrimarginatus, AMS I.45300.288; (G) Paracheilinus lineopunctatus, AMS I.45300.194; (H) Paracheilinus mccoskeri, AMS I.45300.185. Scale bars represent 2.5 mm. Abbreviations: pp, posterior process; sut, suture; p. rays, pelvic rays; p. sp, pelvic spine; iw, inner wing; cp, central part; evw, external ventral wing; c. evw, curvature of external ventral wing.

Of the aforementioned species, C. apterygia appears most closely related to C. earlei (Figs 2C-D \& 3B). Both species share a similar, purple-striped pattern, a rhomboidal to lanceolate caudal fin in males, and essentially the same meristic data. The horizontal-striped pattern is unusual for species of Cirrhilabrus, and aside from C. apterygia and C. earlei, and is also found in the distantly related C. marjorie Allen, Randall \& Carlson, 2003 (Fig. 3C). However, Cirrhilabrus apterygia is readily separated from C. earlei and all congeners in lacking pelvic fins and in having horizontal stripes that run along the isthmus to the anal-fin origin. On the basis of molecular sequence data, C. apterygia is more closely related to C. rubrisquamis sensu lato, C. wakanda, C. sanguineus, and C. blatteus from the western Indian Ocean (Tea et al. 2021b). Several species of Pseudocheilinus (in particular P. octotaenia Jenkins, 1901; Fig. 3D) superficially resemble C. apterygia in colour pattern, but members of Pseudocheilinus are readily separated from Cirrhilabrus in having 6 (versus 5) branchiostegals, a longer second anal-fin spine than third (except in C. laboutei Randall \& Lubbock, 1982), and the posterior margin of the preopercle smooth (except finely serrate on lower margin in P. hexataenia Bleeker, 1857).

The scales and several osseous elements of $C$. apterygia are unusual in that they retain and/or develop purple pigmentation in preservation (Fig. 2E-F). This characteristic is most obvious in the pigmented body scales, dorsalfin spines and rays, the preopercle, and several craniofacial bones. The phenomenon was first noted by Springer \& Randall (1974) in C. blatteus, and later again by Randall (1995) in C. rubrisquamis sensu lato and C. sanguineus. Randall (1999) also made note of bone purpling in the opercle of the lesser known Pseudocheilinus dispilus Randall ,1999, and in fin rays and spines of some (but not all) individuals of P. ocellatus Randall, 1999. Tea et al. (2018, 2019) reported purple craniofacial bones and scales for C. earlei (Fig. $2 \mathrm{G}-\mathrm{H}$ ) and C. wakanda. The phenomenon was previously known only for several species of cirrhilabrin labrids but was recently found to occur in at least two species of Plectranthias (Plectranthias purpuralepis Tang, Lai \& Ho, 2020 and Plectranthias sp. 1 [Tang et al. 2020; Gill et al. 2021, respectively]). Here we further expand this to include C. apterygia, C. lanceolatus, and C. roseafascia - the latter two species were not previously known to develop purple colouration in preservation (evident in some freshly preserved males). The mechanism responsible for the persistence of purple in preservation is still unclear, as are its distribution across acanthomorph taxa and its potential implications for phylogenetic inference. At least within Cirrhilabrus, the character appears plesiomorphic for the C. jordani complex, occurring in all species except $C$. jordani and C. shutmani. 


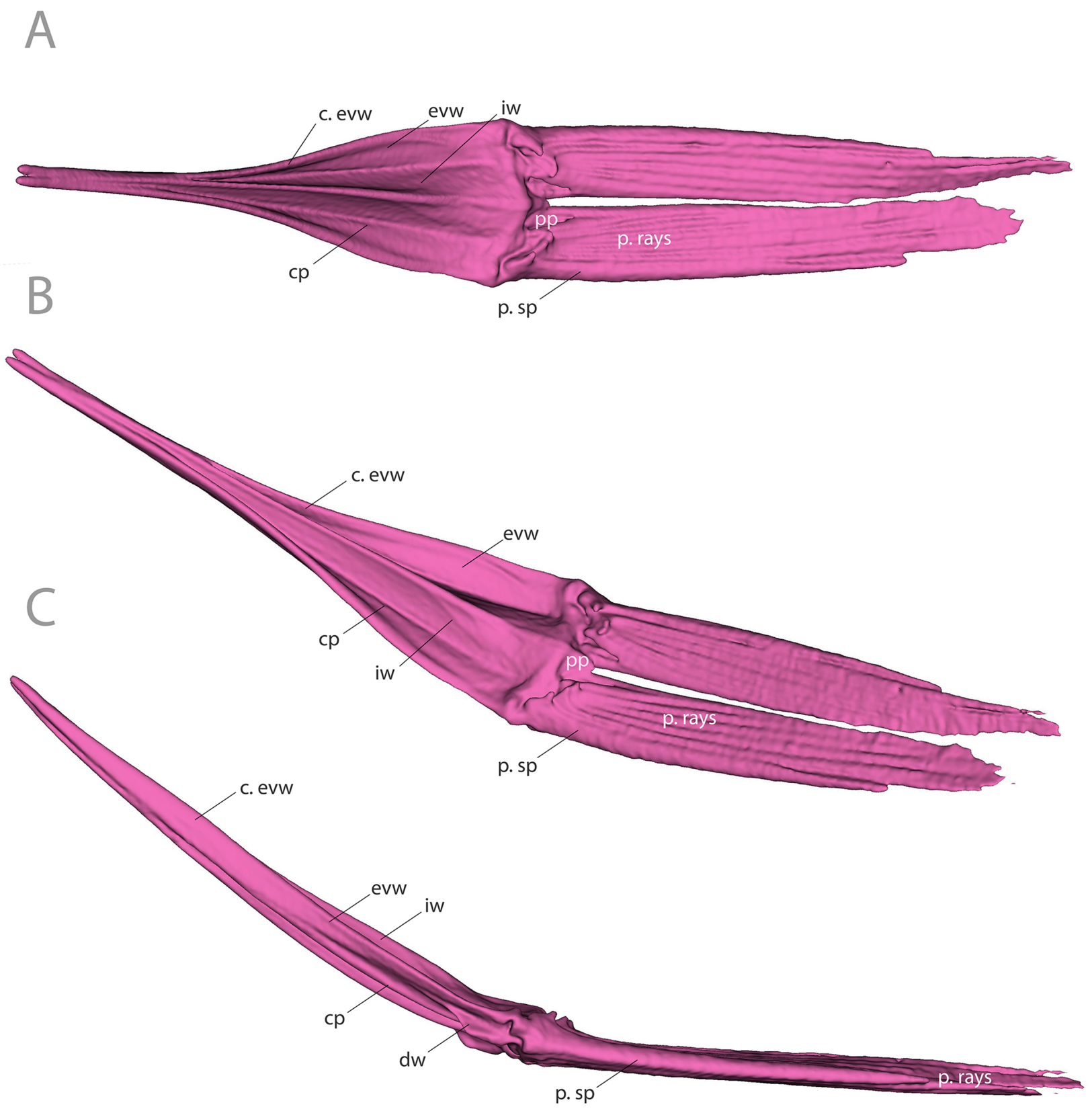

FIGURE 6. $\mu \mathrm{CT}$ scanned pelvic girdle of Paracheilinus octotaenia (uf:fish:186029; MorphoSource). (A and B) ventral view; (C) lateral view (left side). Scale bar represents $2.5 \mathrm{~mm}$. Abbreviations: pp, posterior process; p. rays, pelvic rays; p. sp, pelvic spine; dw, dorsal wing; iw, inner wing; cp, central part; evw, external ventral wing; c. evw, curvarture of external ventral wing.

\section{Cirrhilabrin pelvic girdle}

The pelvic girdle of the cirrhilabrin labrids consists of bilaterally paired basipterygia, each articulating with one spine and five segmented rays on their posterior margins. The medial processes of the two halves are strongly united by bony interdigitating sutures (as described by Stiassny \& Moore 1992). The central processes are separated by a narrow gap before uniting anteriorly. In most cases, anterior processes are almost imperceptible or absent entirely. No apparent ventral wings are present. The external ventral wings are well developed, tapering anteriorly, and with the edges curling ventrally (except for Paracheilinus; see below). 

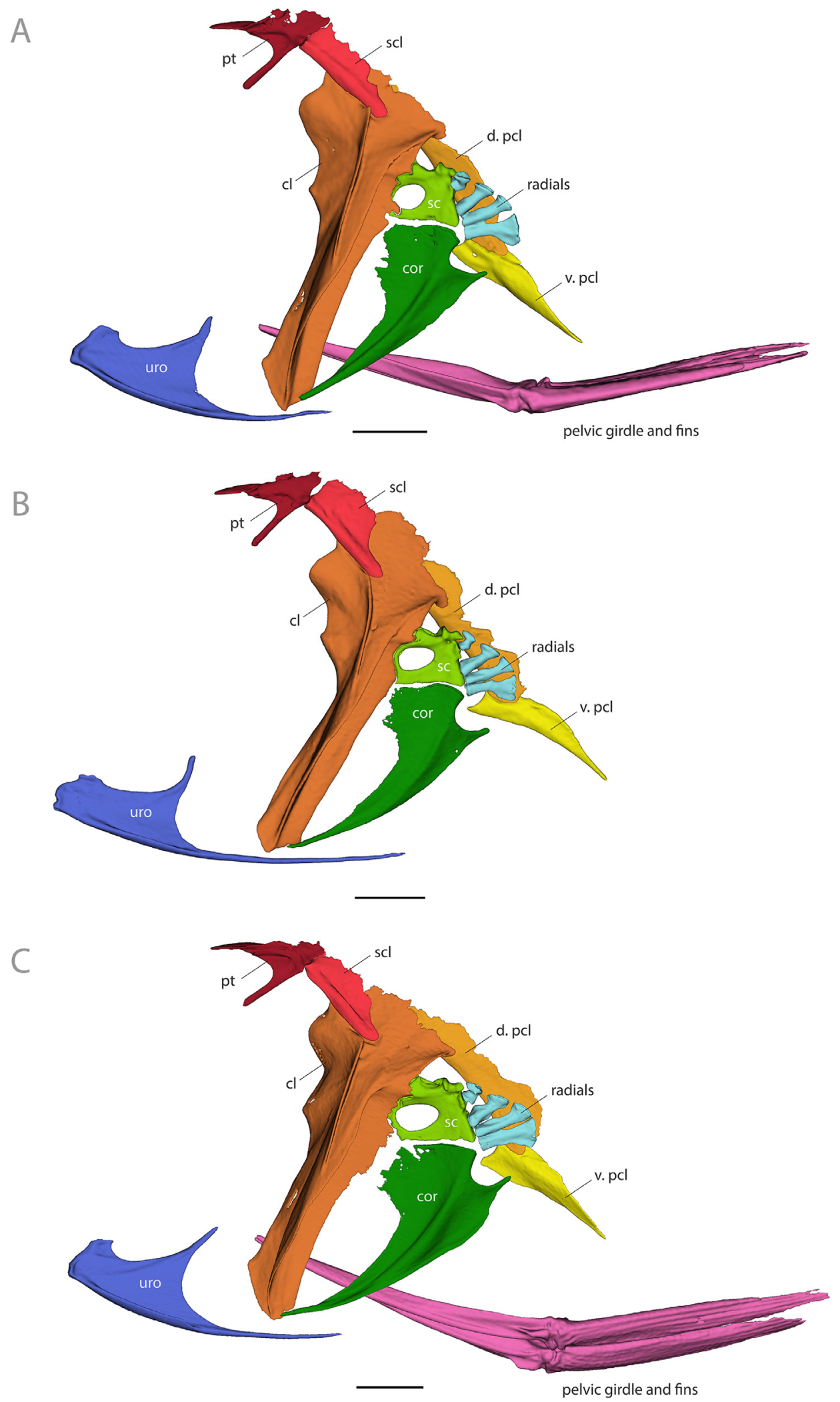

FIGURE 7. $\mu \mathrm{CT}$ scanned pectoral girdle and associated structures of cirrhilabrin labrids (left facing lateral view). (A) Cirrhilabrus solorensis, AMS 1.46121-036 (ark:/87602/m4/392169; MorphoSource); (B) Cirrhilabrus apterygia, NMV A 29675-010 (ark:/87602/m4/392175; MorphoSource); (C) Paracheilinus octotaenia, (uf:fish:186029; MorphoSource). Scale bars represent $2 \mathrm{~mm}$. Abbreviations: uro, urohyal; cor, coracoid; sc, scapula; cl, cleithrum; d. pcl, dorsal postcleithrum; v. pcl, ventral postcleithrum; scl, supracleithrum; pt, posttemporal. 

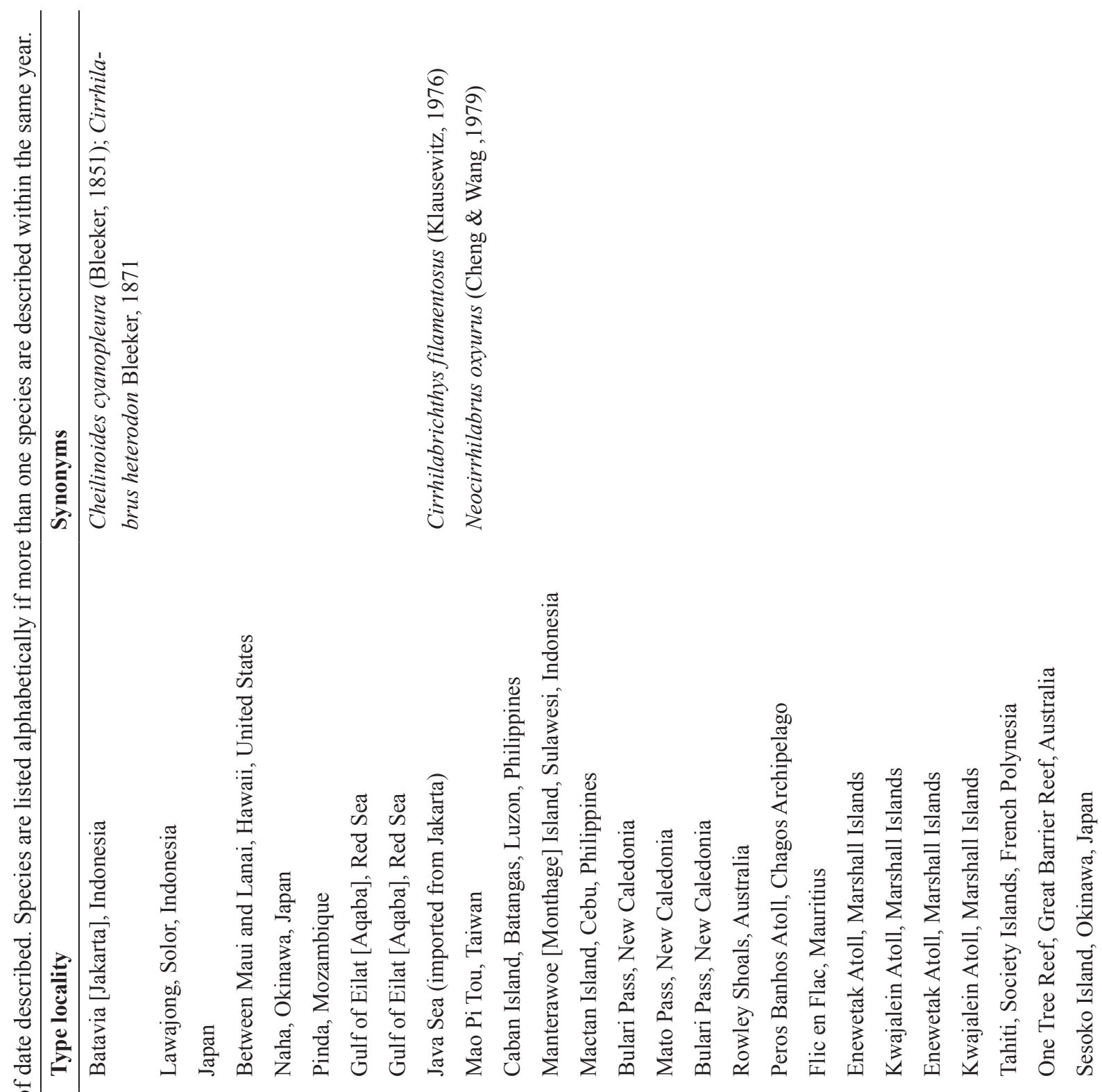

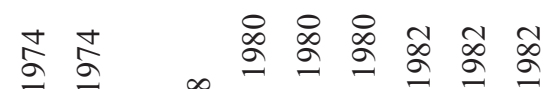

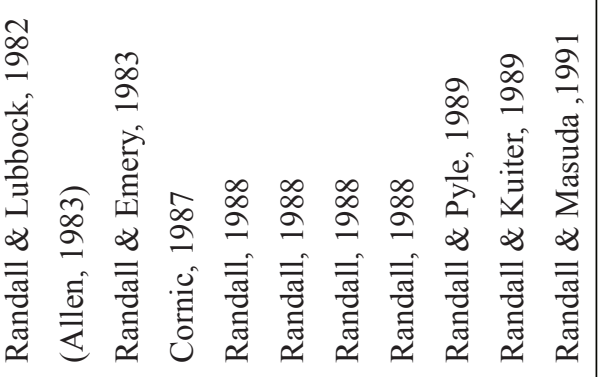




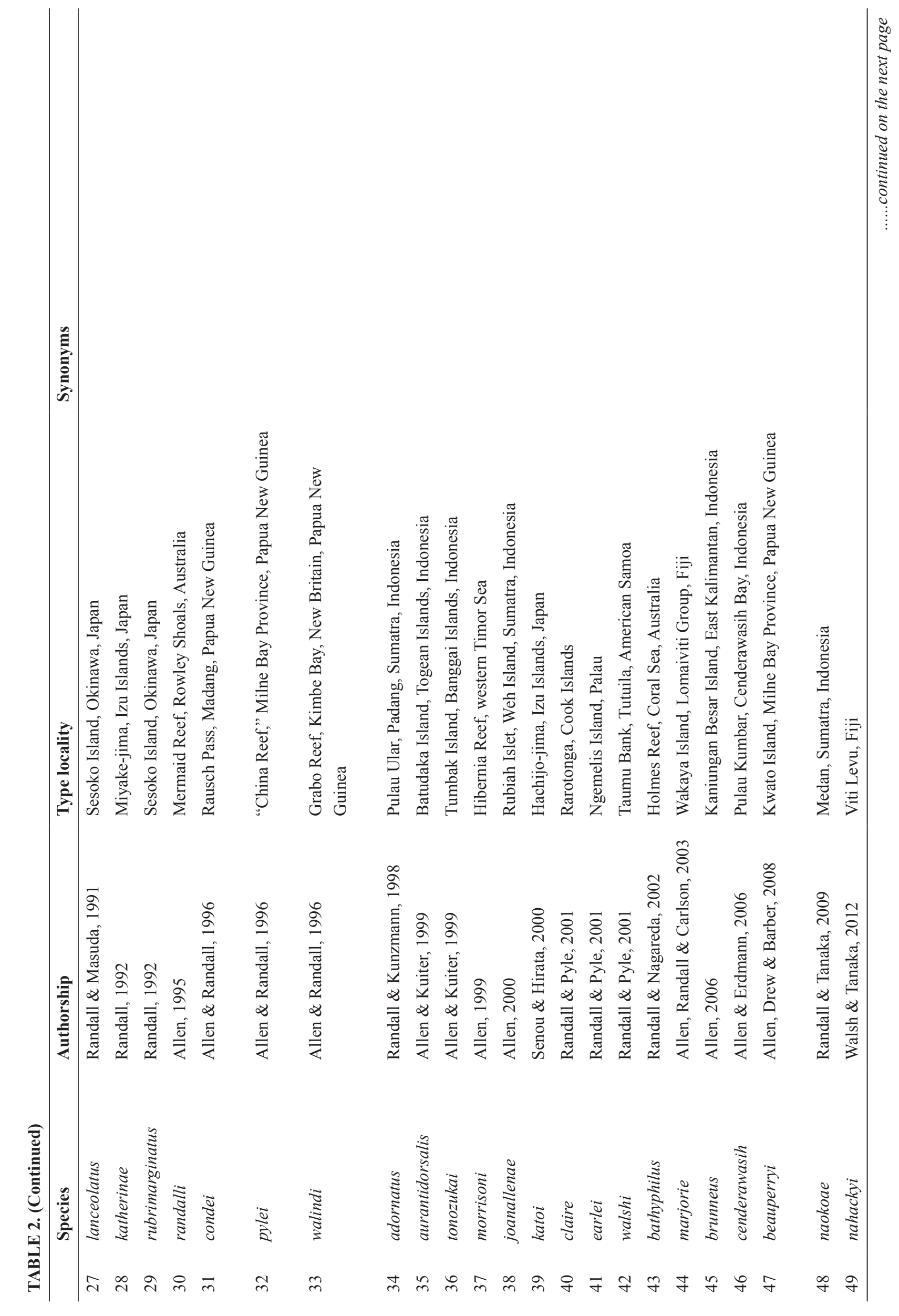




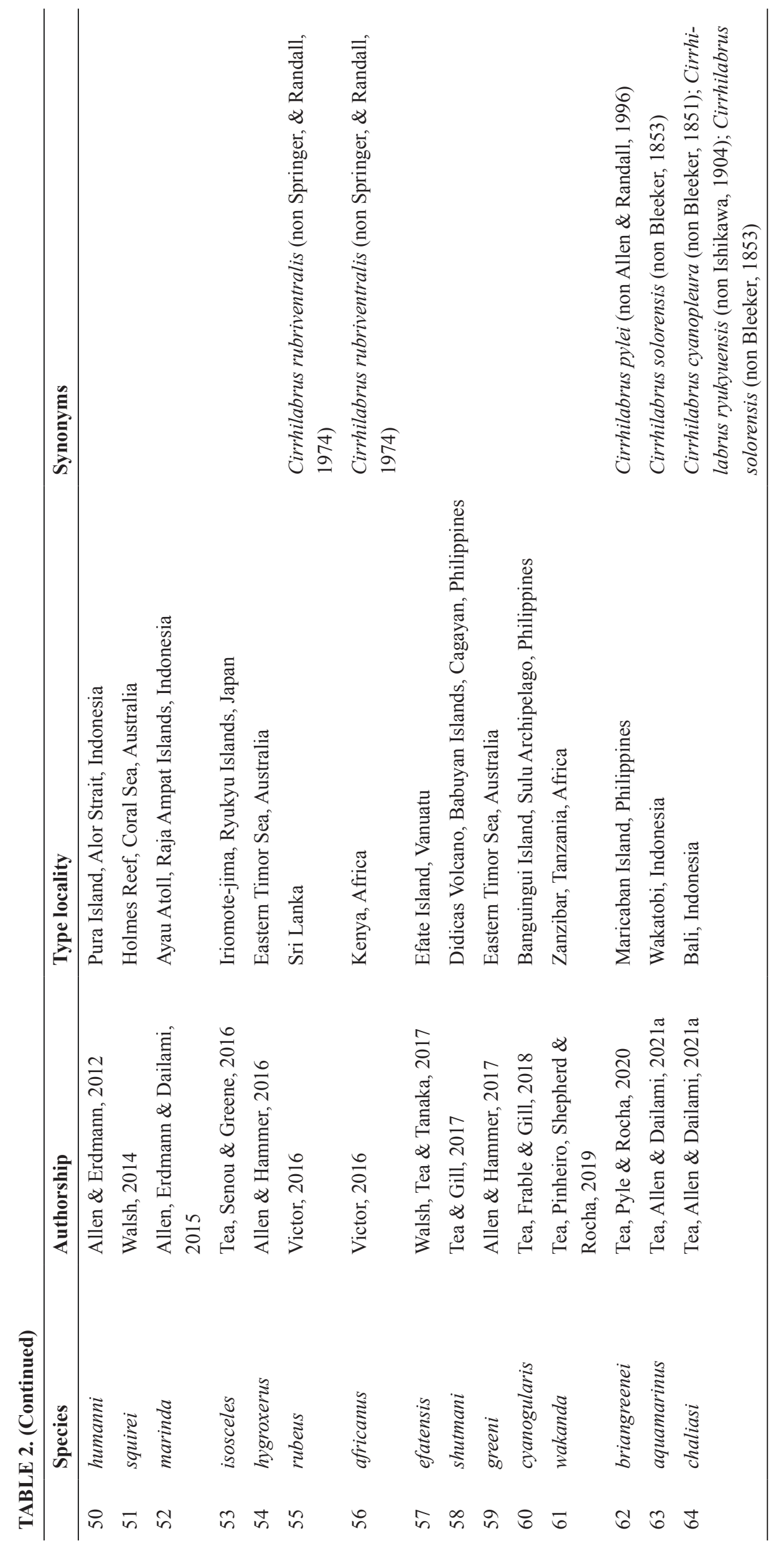


Comparisons. The basic shape of the cirrhilabrin pelvic girdle is similar to those of other labrids (Russell 1988; Bellwood 1994), lying sub-thoracically in a dorsally inclined position away from the ribs. A strong ligamentous association between the pelvic girdle and the ventral postcleithrum (i.e., postcleithral ligament) is present. Although narrowing of the anterior pelvic girdle is typical of other labrids, the extent of external ventral wing curling requires further investigation across other labrid groups. In Paracheilinus, this condition is modified such that the external ventral wing curvature converges along the mid-line, forming a shallow canal that extends along the anterior half to two-thirds the length of the pelvic girdle (Figs. 5G-H \& 6). We interpret this derived condition as a synapomorphy uniting Paracheilinus. Although not immediately associated, the anterior tip of the pelvic girdle lies at a vertical with the lower ramus of the urohyal. The general "bat wing shape" sensu Kusaka (1974) of the cirrhilabrin urohyal is not unlike those of other labrids, but with the lower ramus tapered and elongate, and with about the distal third extending past the cleithrum and the coracoids (Fig. 7). Among labrids, this character is shared with several other groups, including the cheilines (Westneat 1993) and several julidine genera (Halichoeres Rüppel, 1835, Stethojulis Günther, 1861, and Thalassoma Swainson, 1839; Kusaka 1974).

In Cirrhilabrus apterygia, the pelvic girdle, fin rays, and all ligamentous associations with the pectoral girdle are lost. Among labrid fishes, only the odacine Siphonognathus argyrophanes Richardson, 1858 is reported to lack pelvic fins and girdles, a condition which we interpret here as homoplasious and autapomorphic for the two species. Mechanisms for the loss of pelvic elements in C. apterygia are unknown, though similar abnormalities have been reported in other species of Cirrhilabrus (Tea et al. 2021b). These may occur naturally as rare congenital defects, but with these mutations fixed in the range-restricted $C$. apterygia as a result of genetic drift. The study of pelvic anatomy in labrid fishes has received comparatively little attention, and more work is needed to explore pelvic homology across different labrid groups and their implications for phylogenetic relationships.

\section{Valid species of Cirrhilabrus}

Allen et al. (2015) listed 51 valid species of Cirrhilabrus. The genus has since grown to include 63 species, with the present recognition of Cirrhilabrus apterygia bringing the number of valid species to 64 . Although a comprehensive taxonomic treatment of the genus is lacking, systematic studies have been done in parts. These include diagnoses of species complexes (see Tea et al. 2016; Walsh et al. 2017; Tea \& Gill 2017; Tea et al. 2018; Tea et al. 2020), taxonomic revisions (Victor 2016; Tea et al. 2021a), and molecular phylogenomic studies (Tea et al. 2021b). The need for a generic revision of Cirrhilabrus is made clear by the rapidly growing body of literature in recent years, with the number of valid species now exceeding that of any other labrid genus. This number is expected to grow, with several species in need of closer taxonomic evaluation (e.g., the pan Indo-Pacific Cirrhilabrus exquisitus and the western Indian Ocean Cirrhilabrus rubrisquamis sensu lato, in prep. by the first author). Until then, we provide a table of recognised species of Cirrhilabrus, including their synonyms and type localities (Table 2).

\section{Acknowledgements}

We thank A. Hay and K. Parkinson (AMS), G. Moore and M. Allen (WAM), M. Gomon and D. Bray (NMV), and H. H. Tan and K. Lim (ZRC) for curatorial assistance, loan of specimens, and provision of registration numbers. We thank R. Flavel for advice on the use, and maintenance of UNE's $\mu$ CT-scanner, as well as E. Stanley, and Z. Randall for providing access to $\mu \mathrm{CT}$ scans of Pseudocheilinus octotaenia through Morphosource.org. T. Buser, K. Cohen, and J. Huie provided useful discourse regarding $\mu \mathrm{CT}$ scanning and help with initial scans. We also thank R. H. Kuiter, K. Nishiyama, M. Rosenstein, and H. H. Tan for providing excellent photographs used in this study. F. Walsh and two anonymous reviewers provided helpful comments that improved the quality of this manuscript. S. Y. W. Ho provided funding for open access.

\section{References}

Allen, G.R. (1983) A new genus and species of wrasse (Pisces: Labridae) from Rowley Shoals, Western Australia. Revue Française d'Aquariologie Herpétologie, 10 (2), 43-46.

Allen, G.R. (2018) Field Guide to Marine Fishes of Tropical Australia and South-east Asia. Fifth Edition. Western Australian 
Museum, Perth, 287 pp.

Allen, G.R., Erdmann, M.V. \& Dailami, M. (2015) Cirrhilabrus marinda, a new species of wrasse (Pisces: Labridae) from eastern Indonesia, Papua New Guinea, and Vanuatu. Journal of the Ocean Science Foundation, 15, 1-15. https://doi.org/10.5281/zenodo.896902

Allen, G.R. \& Russell, B.C. (1986) Faunal surveys of the Rowley Shoals, Scott Reef and Seringapatam Reef, Northwestern Australia: Part VII. Fishes. Records of the Western Australian Museum, Supplement 25, 75-103.

Allen, G.R. \& Steene, R.C. (1987) Reef Fishes of the Indian Ocean. T. F. H. Publications, Neptune City, New Jersey, 240 pp.

Almeida, L.A.H., Nunes, L.A., Bitencourt, J.A., Molina, W.F. \& Affonso, P.R.A.M. (2017) Chromosomal evolution and cytotaxonomy in wrasses (Perciformes; Labridae). Journal of Heredity, 108 (3), 239-253. https://doi.org/10.1093/jhered/esx003

Bannikov, A.F. \& Carnevale, G. (2010) Bellwoodilabrus landinii n. gen., n. sp., a new genus and species of labrid fish (Teleostei, Perciformes) from the Eocene of Monte Bolca. Geodiversitas, 32 (2), 201-220. https://doi.org/10.5252/g2010n2a2

Bellwood, D.R. (1994) A phylogenetic study of the parrotfishes family Scaridae (Pisces: Labroidei), with a revision of genera. Records of the Australian Museum, Supplement 20, 1-86. https://doi.org/10.3853/j.0812-7387.20.1994.51

Buser, T.J., Boyd, O.F., Cortés, Á., Donatelli, C.M., Kolmann, M.A., Luparell, J.L., Pfeiffenberger J.A., Sidlauskas, B.L. \& Summers, A.P. (2020) The natural historian's guide to the CT galaxy: step-by-step instructions for preparing and analysing computed tomographic (CT) data using cross-platform, open access software. Integrative Organismal Biology 2 (1), obaa009. https://doi.org/10.1093/iob/obaa009

Cowman, P.F., Bellwood, D.R. \& van Herwerden, L. (2009) Dating the evolutionary origins of wrasse lineages (Labridae) and the rise of trophic novelty on coral reefs. Molecular Phylogenetics and Evolution, 52 (3), 621-631. https://doi.org/10.1016/j.ympev.2009.05.015

Fedorov, A., Beichel, R., Kalpathy-Cramer, J., Finet, J., Fillion-Robin, J.-C., Pujol, S., Bauer, C., Jennings, D., Fennessy, F., Sonka, M., Buatti, J., Aylward, S., Miller, J.V., Pieper, S. \& Kikinis, R. (2012) 3D Slicer as an image computing platform for the Quantitative Imaging Network. Magnetic Resonance Imaging, 30 (9), 1323-1341. https://doi.org/10.1016/j.mri.2012.05.001

Gill, A.C., Pogonoski, J.J., Moore, G.I. \& Johnson, J.W. (2021) Review of Australian species of Plectranthias Bleeker and Selenanthias Tanaka (Teleostei: Serranidae: Anthiadinae), with descriptions of four new species. Zootaxa, 4918 (1), 1-116. https://doi.org/10.11646/zootaxa.4918.1.1

Hoese, D.F., Bray, D.J., Paxton, J.R. \& Allen, G.R. (2006) Fishes. In: Beesley, P.L. \& Wells, A. (Eds.), Zoological Catalogue of Australia. Vol. 35. Parts 1-3. ABRS \& CSIRO Publishing, Canberra, pp. xxiv + 1-1670, pp. xxi +671-1472, pp. xxi + 1473-2178.

International Commission on Zoological Nomenclature. (1999) International Code of Zoological Nomenclature. Fourth Edition. International Trust for Zoological Nomenclature, London. xxix $+306 \mathrm{pp}$.

Kasuka, T. (1974) The Urohyal of Fishes. University of Tokyo Press, Japan, 320 pp.

Kuiter, R.H. (2010) Labridae Fishes: Wrasses. Aquatic Photographics, Seaford, 400 pp.

Parenti, P. \& Randall, J.E. (2000) An annotated checklist of the species of labroid fish families Labridae and Scaridae. Ichthyological Bulletin, 68, 1-97.

Parenti, P. \& Randall, J.E. (2018) A checklist of wrasses (Labridae) and parrotfishes (Scaridae) of the world: 2017 update. Journal of the Ocean Science Foundation, 30, 11-27. https://doi.org/10.5281/zenodo. 1247552

Randall, J.E. (1995) A review of the wrasses of the genus Cirrhilabrus (Perciformes: Labridae) from the western Indian Ocean. Revue Française d'Aquariologie Herpétologie, 22 (1/2), 19-26.

Randall, J.E. (1999) Revision of the Indo-Pacific labrid fishes of the genus Pseudocheilinus with descriptions of three new species. Indo-Pacific Fishes, 28, 1-34.

Randall, J.E. \& Masuda, H. (1991) Two new labrid fishes of the genus Cirrhilabrus from Japan. Revue Française d'Aquariologie Herpétologie, 18 (2), 53-60.

Roux-Estève, R. \& Fourmanoir, P. (1955) Poissons capturés par la mission de la “Calypso" en Mer Rouge. Annales de l'Institut Océanographique, Nouvelle Série, 30 (7), 195-203.

Russell, B.C. (1988) Revision of the labrid fish genus Pseudolabrus and allied genera. Records of the Australian Museum, Supplement 9, 1-72. https://doi.org/10.3853/j.0812-7387.9.1988.95

Sabaj, M.H. (2020) Codes for natural history collections in ichthyology and herpetology. Copeia, 108 (3), $593-669$. https://doi.org/10.1643/ASIHCODONS2020

Schultz, L.P., Chapman, W.M., Lachner, E.A., \& Woods, L.P. (1960) Fishes of the Marshall and Marianas Islands. Vol. 2. Families from Mullidae through Stromateidae. United States Government Printing Office, Washington, D.C., 438 pp. https://doi.org/10.5962/bhl.part.17831

Springer, V.G. \& Randall, J.E. (1974) Two new species of the labrid fish genus Cirrhilabrus from the Red Sea. Israel Journal of Zoology, 23 (1), 45-54. 
Stiassny, M.L.J. \& Moore, J.A. (1992) A review of the pelvic girdle of acanthomorph fishes, with comments on hypotheses of acanthomorph intrarelationships. Zoological Journal of the Linnean Society, 104 (3), 209-242.

https://doi.org/10.1111/j.1096-3642.1992.tb00923.x

Swainston, R. (2020) Swainston's Fishes of Australia: The Complete Illustrated Guide. Penguin Books, London, 832 pp.

Tang, C.-N., Lai, N.-W. \& Ho, H.-C. (2020) Plectranthias purpuralepis sp. nov., a new anthiadine perchlet from northern Taiwan (Perciformes: Serranidae). Zootaxa, 4780 (3), 508-522.

https://doi.org/10.11646/zootaxa.4780.3.4

Tea, Y.K., Allen, G.R. \& Dailami, M. (2021a) Redescription of Cirrhilabrus solorensis Bleeker, with description of two new species of fairy wrasses (Teleostei: Labridae: Cirrhilabrus). Ichthyology \& Herpetology, 109 (3), 669-684. https://doi.org/10.1643/i2021022

Tea, Y.K., Frable, B.W. \& Van Der Wal, C. (2018) Redescription and phylogenetic placement of Cirrhilabrus sanguineus Cornic (Teleostei: Labridae), with first documentation of the female form. Zootaxa, 4526 (3), 358-372. https://doi.org/10.11646/zootaxa.4526.3.5

Tea, Y.K. \& Gill, A.C. (2017) Cirrhilabrus shutmani, a new species of fairy wrasse from the Babuyan Islands, northern Philippines (Teleostei: Labridae). Zootaxa, 4341 (1), 77-88. https://doi.org/10.11646/zootaxa.4341.1.6

Tea, Y.K., Pinheiro, H.T., Shepherd, B. \& Rocha, L.A. (2019) Cirrhilabrus wakanda, a new species of fairy wrasse from mesophotic ecosystems of Zanzibar, Tanzania, Africa (Teleostei, Labridae). ZooKeys, 863, 85-96. https://doi.org/10.3897/zookeys.863.35580

Tea, Y.K., Pyle, R.L. \& Rocha, L.A. (2020) A new species of fairy trasse (Teleostei: Labridae: Cirrhilabrus) from mesophotic coral ecosystems of the Verde Island Passage, Philippines. Copeia, 108 (1), 91-102. https://doi.org/10.1643/CI-19-297

Tea, Y.K., Senou, H. \& Greene, B.D. (2016) Cirrhilabrus isosceles, a new species of wrasse (Teleostei: Labridae) from the Ryukyu Archipelago and the Philippines, with notes on the C. lunatus complex. Journal of the Ocean Science Foundation, $21,18-37$. https://doi.org/10.5281/zenodo.53228

Tea, Y.K., Xu, X., DiBattista, J.D., Lo, N., Cowman, P.F. \& Ho, S.Y.W. (2021b) Phylogenomic analysis of concatenated ultraconserved elements reveals the recent evolutionary radiation of the fairy wrasses (Teleostei: Labridae: Cirrhilabrus). Systematic Biology. https://doi.org/10.1093/sysbio/syab012

Van der Laan, R., Eschmeyer, W.N. \& Fricke, R. (2014) Family-group names of Recent fishes. Zootaxa, 3882 (1), 1-230. https://doi.org/10.11646/zootaxa.3882.1.1

Van der Laan, R., Eschmeyer, W.N. \& Fricke, R. (2021) Cumulative addenda to: Family-group names in Recent fishes. Available from: https://www.calacademy.org/sites/default/files/assets/ibss/departments/ichthyology/addendum_family-group_ names_2021-10.pdf (accessed 5 October 2021)

Victor, B.C. (2016) Two new species in the spike-fin fairy-wrasse species complex (Teleostei: Labridae: Cirrhilabrus) from the Indian Ocean. Journal of the Ocean Science Foundation, 23, 21-50. https://doi.org/10.5281/zenodo.163217

Walsh, F., Tea, Y.K. \& Tanaka, H. (2017) Cirrhilabrus efatensis, a new species of wrasse (Teleostei: Labridae) from Vanuatu, South Pacific Ocean. Journal of the Ocean Science Foundation, 26, 68-79. https://doi.org/10.5281/zenodo.570930

Weitzman, S.H. (1974) Osteology and evolutionary relationships of the Sternoptychidae, with a new classification of stomiatoid families. Bulletin of the American Museum of Natural History, 153 (3), 327-478.

Westneat, M.W. (1993) Phylogenetic relationships of the tribe Cheilinini (Labridae: Perciformes). Bulletin of Marine Science, $52(1), 351-394$. 